Portland State University

PDXScholar

6-1-2018

\title{
Mass Accretion and Ozone Reactivity of Idealized Indoor Surfaces in Mechanically or Naturally Ventilated Indoor Environments
}

\author{
Elliott T. Gall \\ Portland State University, gall@pdx.edu \\ Donghyun Rim \\ Pennsylvania State University
}

Follow this and additional works at: https://pdxscholar.library.pdx.edu/mengin_fac

Part of the Materials Science and Engineering Commons, and the Mechanical Engineering Commons Let us know how access to this document benefits you.

\section{Citation Details}

Gall, E. T., \& Rim, D. (2018). Mass accretion and ozone reactivity of idealized indoor surfaces in mechanically or naturally ventilated indoor environments. Building and Environment, 138, 89-97.

This Post-Print is brought to you for free and open access. It has been accepted for inclusion in Mechanical and Materials Engineering Faculty Publications and Presentations by an authorized administrator of PDXScholar.

Please contact us if we can make this document more accessible: pdxscholar@pdx.edu. 
Mass accretion and ozone reactivity of idealized indoor surfaces in mechanically or naturally ventilated indoor environments

Elliott T. Gall ${ }^{1,2}$, Donghyun Rim ${ }^{3}$

${ }^{1}$ Mechanical and Materials Engineering, Portland State University, Portland, OR 97201, USA

${ }^{2}$ Nanyang Technological University and Berkeley Education Alliance for Research in Singapore, Singapore 138602

${ }^{3}$ Architectural Engineering Department, Pennsylvania State University, University Park, PA 16802, USA

${ }^{*}$ Corresponding author: Elliott T. Gall

Email: gall@pdx.edu

\section{Abstract}

In indoor environments, accretion of mass to materials may provide sites for surface chemistry that differ from those of the original material. Since indoor surfaces are a major sink of oxidant gases, surface mass accretion may impact indoor $\mathrm{O}_{3}$ chemistry. In this study, the effect of surface mass accretion on $\mathrm{O}_{3}$ surface deposition was tested by deploying cleaned borosilicate glass plates in two types of indoor environments: a mechanically ventilated (MV) office and a naturally ventilated (NV) residence located in Singapore. In each environment, seven replicate glass plates and one field blank were deployed for between 7-56 days and examined in a laboratory chamber for $\mathrm{O}_{3}$ deposition rate and surface reaction probability. Average mass accretion to plates, deployed in a horizontal position and including deposited particles, was $10.6 \mathrm{mg} /\left(\mathrm{m}^{2} \mathrm{~d}\right)$ in the MV office vs. $18.5 \mathrm{mg} /\left(\mathrm{m}^{2} \mathrm{~d}\right)$ in the $\mathrm{NV}$ residence and the comparison is at the threshold of statistical significance $(p=0.054)$. Ozone reactivity to the plates increased in magnitude and persistence with longer plate deployment. Ozone reaction probabilities to cleaned plates prior to deployment ranged $[0.06-0.74] \times 10^{-6}$ for two hours of observable removal whereas plates deployed for 56 days ranged [0.15-1.2] $\times 10^{-6}$ for four hours of observable removal. Regressions of cumulative $\mathrm{O}_{3}$ removed during chamber tests vs. mass accreted show removal of $4.3 \mathrm{nmol} \mathrm{O} / 3 \mathrm{mg}$ for the $\mathrm{NV}$ residence and $2.4 \mathrm{nmol} \mathrm{O}_{3} / \mathrm{mg}$ for the MV office. These results imply that accretion of mass to surfaces may alter indoor $\mathrm{O}_{3}$ transport and transformation pathways.

\section{Introduction}

Exposure to elevated $\mathrm{O}_{3}$ is associated with cardiovascular effects, asthma, and increases in daily mortality [1-3]. Humans are exposed to $\mathrm{O}_{3}$ primarily in the small fraction of the atmosphere contained inside built environments. The predominant source of indoor $\mathrm{O}_{3}$ is from outdoor air where $\mathrm{O}_{3}$ is formed due to photochemical reactions that involve sunlight, volatile organic compounds (VOCs), $\mathrm{NO}_{\mathrm{x}}$, and carbon monoxide [4]. Indoor $\mathrm{O}_{3}$ levels are $20-70 \%$ that of outdoor levels mainly due to chemical reactions with interior surfaces that remove $\mathrm{O}_{3}$ from air [5]. In spite of lower indoor $\mathrm{O}_{3}$ levels, total indoor $\mathrm{O}_{3}$ exposures typically exceed outdoor exposures because of the time spent in indoors [6-8]. Epidemiological studies suggest a safe level of exposure to $\mathrm{O}_{3}$ is below $10 \mathrm{ppb}$ [9], a level which indoor spaces routinely exceed 
[5]. Certain surface $\mathrm{O}_{3}$ reaction pathways may generate byproducts, effectively trading indoor $\mathrm{O}_{3}$ for other harmful or irritating byproducts [10]. There is interest in developing beneficial indoor surface $\mathrm{O}_{3}$

40 pathways to passively reduce human exposure to $\mathrm{O}_{3}$, if removal results in no byproducts or only benign

41 byproducts [11,12].

42 In a typical indoor space, many exposed surfaces can react with $\mathrm{O}_{3}$. A seminal study of indoor $\mathrm{O}_{3}$

43 dynamics reported ozone decay constants for homes and decomposition rates for specific indoor surfaces

44 [13]. Subsequent studies have expanded our knowledge of indoor $\mathrm{O}_{3}$ dynamics by characterizing reaction 45 rates with a wide variety of building materials [11,12,14-22], as well as identifying byproduct formed 46 from material- $\mathrm{O}_{3}$ reactions $[10,23-26]$. Outcomes of studies of material- $\mathrm{O}_{3}$ interactions generally report

47 material reactivity as a deposition velocity, $v_{d}$ [27], or a reaction probability, $\gamma$ [28]. Such

48 parameterizations enable material balance models of indoor $\mathrm{O}_{3}$ that describe fate, transport, and 49 transformation of $\mathrm{O}_{3}$ and $\mathrm{O}_{3}$ reaction byproducts [16,29-31].

50 As materials react with $\mathrm{O}_{3}$, so-called “aging” phenomena are observed where ozone reactivity decreases 51 with time. Over short time-scales $(<10 \mathrm{~h})$, this has been observed in chamber tests where materials are 52 exposed to elevated $\mathrm{O}_{3}$ that is alternated with air free of $\mathrm{O}_{3}$ on a time scale of hours [13]. Under such 53 conditions, materials generally exhibit a reduction in material- $\mathrm{O}_{3}$ reactivity with increasing exposures or 54 exposure periods $[14,18,21]$. This behavior is ascribed to exhaustion of reaction sites on the surface after 55 initial $\mathrm{O}_{3}$ exposure, with subsequent $\mathrm{O}_{3}$ removal rate-limited by diffusion of new reaction sites to the 56 surface [32].

57 Over longer time-scales, e.g., months of deployment in real buildings, prior studies demonstrate 58 variability in impacts on magnitudes of material- $\mathrm{O}_{3}$ reactivity. In a study where four materials were 59 placed in field sites over a period of $\sim 6$ months, material- $\mathrm{O}_{3} v_{d}$ increased modestly for ceiling tile, 60 decreased for carpet, and was largely unchanged for activated carbon and painted drywall [25]. Another 61 study of material- $\mathrm{O}_{3}$ reaction showed that for three building materials deployed in an occupied office 62 environment, $v_{d}$ decreased for painted drywall after 1 and 2 months of deployment while $v_{d}$ for carpet and 
ceiling tile decreased after 1 month, subsequently increasing to higher than the "fresh" reactivity after 2 months of placement in the field [18]. These studies posit that deposition processes occurring in the indoor environment provide a mechanism by which gases and particles may associate with the surface, in some cases replenishing $\mathrm{O}_{3}$ surface reaction sites.

Accretion of low-volatility gases, particles, water, inorganic species and elemental carbon create a surface film on indoor surfaces [33]. Previous studies show that sorption of low-volatility compounds and deposition of particles impact the chemical composition of building and indoor surfaces. Studies of indoor and exterior window surfaces demonstrate that window surfaces act as a reservoir for alkanes, polycyclic aromatic hydrocarbons, polychlorinated biphenols, and pesticides [34,35]. Another study investigated surface film formation by heating glass and aluminum materials that were initially clean and then exposed to successively longer periods of an indoor air matrix [36]. Time exposed to indoor air was a strong determinant of ultrafine particle formation, due to condensation of SVOCs that were volatilized from the material during a controlled heating process. Settling of indoor dust may also alter surface chemical composition. A study of the $\mathrm{O}_{3}$ reactivity of indoor dust shows high rates of $\mathrm{O}_{3}$ removal to dust, with increases of $\mathrm{C}_{7}-\mathrm{C}_{9}$ aldehydes and other reaction byproducts produced from $\mathrm{O}_{3}$-dust reactions [32].

Given the importance of indoor surfaces in governing indoor $\mathrm{O}_{3}$ and $\mathrm{O}_{3}$ reaction byproduct concentrations, the objective of the present study is to investigate dynamics of surface mass accretion and the resulting reactivity of indoor surfaces. This study addresses this knowledge gap by measuring how surface film accretion impacts ozone deposition and surface reaction probability. While other studies have explored this phenomena, this work uses glass plates as an idealized surface that reduces confounders such as initial material composition, material aging, and material cleanliness in subsequent studies of accreted mass. However, glass is also a common indoor material such that mass accretion can be taken as representative of what can occur on certain surfaces in real indoor environments. The study results will provide baseline data for how mass is accreted to initially inert, clean materials and subsequent ozone- 
87 surface reaction dynamics in two typical indoor environments: 1) a naturally ventilated residence and 2) a

88 mechanically ventilated office.

892 Methods

$90 \quad 2.1$ Glass plates

91 Borosilicate glass plates were selected as surfaces to facilitate investigations of the dynamics of the mass

92 accumulated to indoor surfaces (i.e., a surface film of deposited particles and/or sorbed gases from indoor

93 air) and resulting ozone reactivity of the glass plate/surface film. Borosilicate glass plates were selected

94 due to the inertness and smoothness of glass and the known low uptake of $\mathrm{O}_{3}$ to clean glass [19,30]. Glass

95 provides a low baseline from which subsequent signals of $\mathrm{O}_{3}$ uptake to accreted masses can be more

96 readily differentiated. Borosilicate glass plates (McMaster-Carr) with horizontal projected surface area of

$97232 \mathrm{~cm}^{2}(15.24 \mathrm{~cm} \times 15.24 \mathrm{~cm}$, thickness $=0.3175 \mathrm{~cm})$ were used in this investigation.

98 Prior to deployment in the field, sixteen glass plates were cleaned by washing with laboratory-grade soap

99 and a soft sponge. All glass plates were then rinsed in water three times to ensure no soap film remained.

100 Glass plates were then cleaned with a lint-free wipe (Kimtech Kimwipes, Kimberly-Clark Professional)

101 dipped in high purity isopropyl alcohol (Levinson Scientific and Chemicals, IPA Technical Grade >99\%)

102 and allowed to air dry in a fume hood in a vertical position. After drying, all plates were heated with a

103 heat gun for fifteen minutes to vaporize remaining solvent or other sorbed volatile species. All plates were

104 then placed in a chamber apparatus (details in Section 2.4) and were passivated of ozone reaction sites by

105 supplying approximately $500 \mathrm{ppb}$ of ozone to the chamber for $8 \mathrm{~h}$. All plates were then immediately

106 weighed (see section 2.3) to obtain the initial mass of the plate and placed in polypropylene storage bags

107 for $\sim 1$ week until deployment into the field environments. Tests of $\mathrm{O}_{3}$ reactivity were made for two

108 randomly selected plates to establish a baseline ozone deposition velocity $\left(v_{d}\right)$ to a clean plate.

$109 \quad 2.2$ Deployment and collection of glass plates

110 Seven test plates and one field blank plate were randomly selected from the set of sixteen plates for

111 concurrent deployment to two indoor environments: a naturally ventilated (NV) residential dwelling and a 
112 mechanically ventilated (MV) office building. In both environments, the seven plates were placed on wire

113 racks such that the plates were horizontal to the ground (see Fig. S1 for an image of the deployment). A

114 field blank, a glass plate prepared as described in Section 2.1, but deployed to the field environment in the 115 polypropylene bag, was deployed to each of the field locations. In both locations, the temperature $\left({ }^{\circ} \mathrm{C}\right)$, 116 relative humidity (\%), and light (lux) levels were recorded in 5-minute interval (HOBO U12-012, Onset 117 Computer Corporation), shown in Fig. S2. In both the MV and NV location, plates were deployed for a 118 total of 56 days. Test glass plates were collected at approximately weekly intervals while a field blank 119 was collected after deployment for three weeks (NV residence) and eight weeks (MV office).

120 Racks used to support glass plates were placed in unobtrusive locations that were representative of typical 121 tabletop height surfaces in each environment. Racks were used to facilitate testing of ozone removal to 122 the downward facing side of the plate subsequent to the upward face. However, no observable $\mathrm{O}_{3}$ removal 123 could be discerned to the downward facing plate. Results presented here are tests where only the upward 124 facing side of the plate was exposed to $\mathrm{O}_{3}$ inside the chamber. In the $\mathrm{MV}$ office building, the wire racks 125 with plates were placed on a desk height table top, typical of an office environment where computer126 related work tasks are conducted. The office building is served by a demand-controlled ventilation system 127 that introduces outdoor air proportional to the amount of carbon dioxide in the space, and includes 128 mechanical systems for filtration (MERV 6-8 rated filters), cooling, and dehumidification. The ventilation 129 rate was not measured during the period of the deployment. The plates were placed on an L-shaped desk, 130 approximately $1 \mathrm{~m}$ in distance from the workstation where an office worker was present during normal 131 working hours. The zone was typically occupied by 5-15 office workers.

132 In the NV residential environment, the racks with the seven test plates and one field blank were placed on 133 a television stand in a living room at approximately $1 \mathrm{~m}$ in height. The residential environment was 134 occupied by two individuals, typically during non-working hours. The zone the plates were placed in was 135 served only by fan-assisted natural ventilation; ventilation and cooling were provided to the space by 136 window opening and fans that were operated to draw outdoor air into the room based on the preference of 

open with fans on during evenings and weekends, and windows closed with fans off during sleeping hours. The ventilation rate was not measured during the period of the deployment.

The two sites investigated were located within $1 \mathrm{~km}$ of each other in vicinity of the National University of Singapore and we expect the outdoor conditions to be similar. We lack accompanying air quality data at the field sites; in general, the Singapore National Environment Association reported Pollutant Standard Index levels of 30-50 across the period of this study, indicating "good” to "moderate” outdoor air quality.

144 In such conditions, indoor particle and ozone concentrations are likely higher for the naturally ventilated residence than the mechanically ventilated office because of no filtration with frequently open windows in

147 the laboratory where analyses occurred. The protocol developed for transporting plates for analysis 148 consisted of wearing new nitrile gloves to carefully place plates into polypropylene bags sized such that 149 there was no contact between the top surface of the plate and the bag. The plate was then placed in a 150 container to be immediately transported, in the same orientation as when placed in the field, to the 151 laboratory for weighing and analysis of ozone removal. It took less than two hours until the samples were 152 analyzed in the laboratory.

\section{$153 \quad 2.3$ Measurement of mass accretion to glass plates}

154 Initial plate mass was measured with an analytical balance (ME204, Mettler Toledo), with an absolute 155 uncertainty of $\pm 0.0001 \mathrm{~g}$. While plates were nominally of uniform dimension and material, each plate was 156 tracked specifically as small variations in initial plate mass were noted $(\mu=170.1751 \mathrm{~g}, \sigma=0.44 \mathrm{~g})$. After

157 deployment to the field and subsequent return to the laboratory, each plate was measured by placing the 158 plate on a clean sheet of weighing paper and allowing the mass reading to stabilize over a period of 159 approximately 1 min and the change in mass from its initial "clean" measurement was noted. The 160 environmental conditions of the laboratory were different from that of both the MV office environment 161 and the NV residence. The 1 min duration was chosen to allow the reading to stabilize from the 
163 the equilibration of sorbed water with the laboratory environment.

164 Average mass accretion rates to the plates deployed in the field were calculated according to eq. 1:

165

$$
\dot{m}=\frac{\left(m_{f}-m_{i}\right)}{t_{d} A}
$$

where $\dot{m}$ is the mass accretion rate to a test plate $\left(\mathrm{g} /\left(\mathrm{m}^{2} \mathrm{~d}\right)\right), m_{f}$ is the final mass accreted to a test plate after a field deployment (g), $m_{, i}$ is the initial mass of a cleaned plate prior to deployment (g), $t_{d}$ is the time duration the plate spent deployed in the field (d), and $A$ is the exposed area of the top surface of the plate $\left(\mathrm{m}^{2}\right)$. Since the bottom surface was also exposed to the environment, the normalization introduces a small error as some mass may have accumulated on the bottom surface. The implications of this assumption are discussed in Section 3.1.

\subsection{Test apparatus}

Ozone deposition velocities were measured in a laboratory chamber apparatus; a schematic of the apparatus is shown in Fig. 1. Compressed laboratory air passed through a membrane dryer that included a 0.1 micron pre-filter (Laman MD-15LS and Laman SAM350-E, Air Parts Center Pte Ltd) to remove particles and water vapor present in the compressed air. Dried, particle-free air was then passed through a packed bed of activated carbon (BPL 6×16, Calgon Carbon) to remove ozone and volatile organic compounds. The air flow was then split into three streams with flow rates set and maintained using mass flow controllers (Omega FMA5500, Omega Singapore). One stream was used to humidify the airflow to the desired setpoint based on the depth of deionized water in the water column and the flowrate through the column. The second stream was an unmodified flow of dry, clean air that was mixed with the humidified stream to maintain the desired relative humidimty $(\mathrm{RH})$ set-point. The third stream passed through a stable ozone generator (U04/97-0066-02, UVP LLC). These three flow streams were recombined prior to entering a temperature controlled enclosure (KBE3.1, Binder GmBH) that was used to 
maintain the air temperature and humidity to constant setpoints. Inside the temperature controlled temperature and RH (U12-012, Onset Computer Corporation).

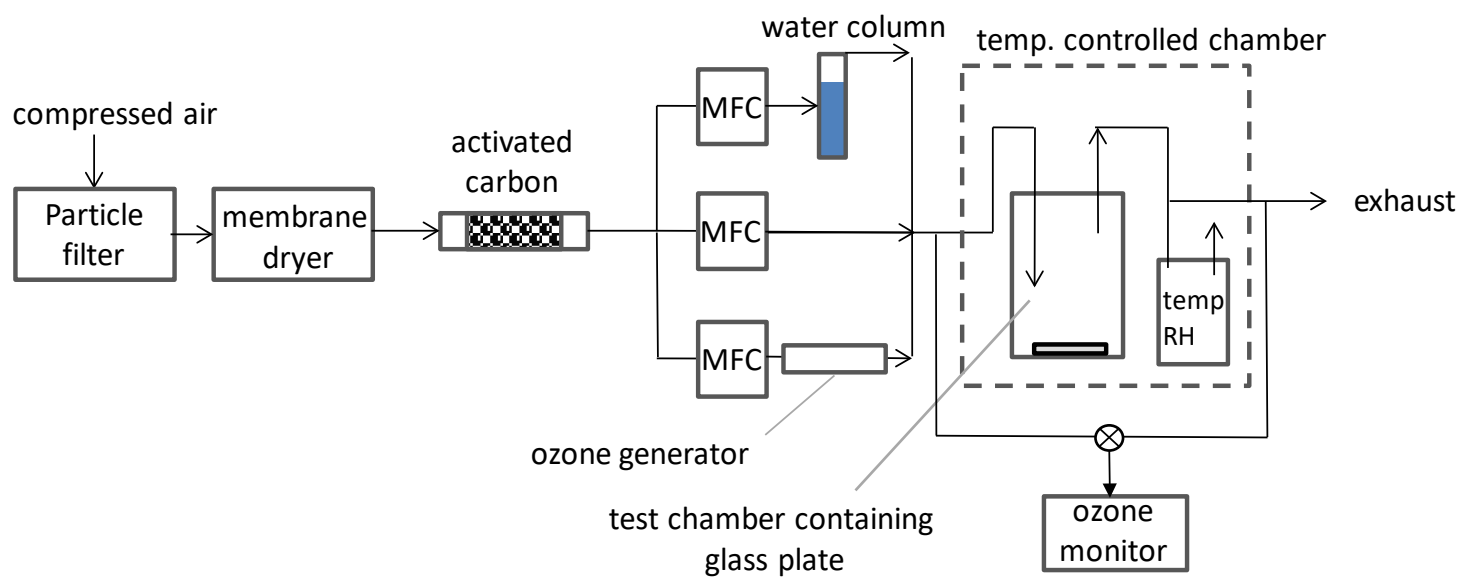

Fig. 1. Schematic of test apparatus for measuring ozone deposition occurring on clean and field deployed glass surfaces. $\mathrm{MFC}=$ mass flow controller, $\mathrm{RH}=$ relative humidity .

\subsection{Experimental protocol}

Prior to a test of a glass plate, a test of background $\mathrm{O}_{3}$ removal of the empty stainless steel chamber was conducted. Ozone was injected into the empty chamber at a stable until steady-state conditions, defined as changing less than $2 \mathrm{ppb}$ in a 20 minute time period [37]. After conducting a background test of an empty chamber, a cleaned (week 0), field-environment deployed plate (weeks 1-7), or field blank glass plate was placed in the chamber and the $\mathrm{O}_{3}$ injection was repeated. Ozone injections when glass plates were present were conducted for a period of four hours; longer test durations were explored but resulted in deposition velocities that were indistinguishable from background removal. A switching valve was used to periodically alternate between inlet and outlet concentrations of ozone (Model 202, 2BTech). Across all experiments, the average (mean \pm 1 std. dev.) temperature and $\mathrm{RH}$ was $25.2 \pm 0.057{ }^{\circ} \mathrm{C}$ and $49.3 \pm 1.8 \%$. Experiments were conducted with an average chamber flowrate of $2.2 \pm 0.1 \mathrm{~L} / \mathrm{min}$ (air exchange rate = $11.5 / \mathrm{h})$. Inlet ozone concentrations to the test chamber were an average $96.8 \pm 2.0 \mathrm{ppb}$. 


\subsection{Data analysis}

\subsubsection{Determination of $v_{d}, v_{t}, \gamma$}

206 The background loss rate $L_{b g}\left(\mathrm{~h}^{-1}\right)$ of ozone was calculated from steady-state data according to eq. 2:

$$
\frac{d C_{\text {outlet }}}{d t}=0=\lambda C_{\text {inlet }}-\lambda C_{\text {outlet }}-L_{\text {bg }} C_{\text {outlet }}
$$

where $C_{\text {inlet }}$ and $C_{\text {outlet }}$ are the inlet and outlet concentrations of ozone (ppb), $t$ is time (h), $\lambda$ is the air exchange rate $\left(\mathrm{h}^{-1}\right)$ and $L_{b g}$ is the background loss rate $\left(\mathrm{h}^{-1}\right)$ to stainless steel chamber surfaces. Ozone $v_{d}$ to background chamber stainless steel surfaces were calculated using the exposed area of the stainless steel chamber surfaces $\left(1810 \mathrm{~cm}^{2}\right)$ and the chamber volume $\left(11,400 \mathrm{~cm}^{3}\right)$. Ozone $v_{d}$ to stainless steel

212 surfaces were, on average, $\sim 0.002 \mathrm{~cm} \mathrm{~s}^{-1}$ and was determined in a background test prior to each

213 experiment. Ozone deposition velocity $\left(v_{d}\right)$ to glass plates was determined using a transient mass balance 214 relationship that was solved numerically for the deposition velocity in 5-min interval, as shown in eq. 3:

$$
v_{d}^{t}=\frac{V}{A_{S}} \cdot \frac{1}{C_{\text {outlet }}^{t}}\left[\lambda\left(C_{\text {inlet }}^{t}-C_{\text {outlet }}^{t}\right)-L_{b g}\left(\frac{A_{B G}-A_{S, p}}{A_{B G}}\right) C_{\text {outlet }}^{t}-\frac{C_{\text {outlet }}^{t}-C_{\text {outlet }}^{t+1}}{\Delta t}\right]
$$

217 chamber $\left(\mathrm{cm}^{3}\right), A_{s}$ is the area of the top and sides of the glass plate $\left(\mathrm{cm}^{2}\right), C_{\text {inlet }}^{t}$ is the ozone concentration 218 entering the chamber at time $\mathrm{t}(\mathrm{ppb}), C_{\text {outlet }}^{t}$ is the ozone concentration exiting the chamber at time $t$ 219 (ppb), $A_{B G}$ is the area of background chamber surface $\left(\mathrm{cm}^{2}\right), A_{S, p}$ is the projected area of the glass plate $220\left(\mathrm{~cm}^{2}\right)$, and all other terms as defined previously.

221 The total molar uptake of ozone to a test glass plate, $\Phi$ (mol), was determined as shown in eq. 4:

$$
\Phi=\sum_{t=1}^{n} v_{d}^{t} \times \bar{C}_{\Delta t} \times A_{S} \times \Delta t
$$


223 where $\bar{C}_{\Delta t}$ is the average ozone concentration $\left(\mathrm{mol} \mathrm{m}^{-3}\right)$ in the chamber during the five-minute period, $\Delta t$,

224 in which $v_{d}^{t}$ is calculated.

225 Ozone deposition velocities were further parameterized according to resistance-uptake theory, where $v_{d}$ 226 can be expressed in terms of a transport limited deposition velocity, $v_{t}\left(\mathrm{~cm} \mathrm{~s}^{-1}\right)$ and a reaction probability, $227 \gamma(-)$, or the fraction of ozone-surface collisions that result in a reaction $[14,28,38]$, shown in eq. 5:

$$
\frac{1}{v_{d}}=\frac{1}{v_{t}}+\frac{4}{\gamma\langle v\rangle}
$$

229 where $\langle v\rangle$ is the Boltzmann velocity $\left(\mathrm{cm} \mathrm{s}^{-1}\right)$.

230 The $v_{t}$ was determined from an experiment in which cleaned glass was coated in a solution of $20 \mathrm{~g}$ of 231 potassium iodide (>99\% purity, Sigma-Aldrich) dissolved in $25 \mathrm{~mL}$ of deionized water. The solution was 232 applied to a cleaned borosilicate glass dish with a small lip. The dish was then dried in the chamber with 233 cleaned, ozone-free air until a solid KI film coated the surface of the dish. An ozone deposition 234 experiment was conducted and the deposition velocity was determined using eq. 2. This condition 235 assumed negligible reaction resistance (i.e., $\frac{4}{\gamma\langle v\rangle} \ll \frac{1}{v_{t}}$ ) such that $v_{d}=v_{t}$. Since fluid dynamic conditions in 236 the chamber were held constant across all experiments, this allowed determination of $\gamma$ in subsequent 237 experiments. The experimentally determined $v_{t}(\mu \pm \sigma=0.57 \pm 0.028 \mathrm{~cm} / \mathrm{s})$ is shown in Fig. S3 and is in 238 general agreement with previously determined values in laboratory [18] and field environments [39].

239 To enable statistical comparison across dynamic estimates of ozone reactivity, we employed a metric that 240 characterized the time-variant reaction probability to enable regression analysis. First-order kinetics were 241 applied to the transient values of the reaction probability as shown in equation 6:

$$
\frac{d \gamma(t)}{d t}=-\beta \times \gamma(t)
$$


243 where $\gamma(t)$ is the time-varying reaction probability (-), $t$ is the time $(\mathrm{min})$, and $\beta\left(\mathrm{min}^{-1}\right)$ is the first-order

244 decay constant of the reaction probability.

245 With the initial condition of $t=0, \gamma(t)=\gamma(t=0)$, the solution to eq. 6 takes the form $y=m x$ where $y$ is

$246-\ln \left(\frac{\gamma(t)}{\gamma(t=0)}\right), m$ is $\beta$, and $x$ is the time during an experiment where reaction probability is being

247 measured. Higher values of $\beta$ indicate a faster decay of the reaction probability than lower values of $\beta$.

$248 \quad$ 2.6.2 Quality assurance

249 Experimental uncertainty in estimates of deposition velocities were determined using a propagation of

250 errors analysis for eq. 3, based on the manufacturer's specifications of instrument error. An uncertainty of

251 the greater of $2 \mathrm{ppb}$ or $2 \%$ was used for the ozone monitor for inlet and outlet ozone measurements, $1.5 \%$

252 of the reading for the mass flow controller for uncertainty on air exchange, while the error introduced due

253 to area and volume measurements of plates was assumed to be $1 \%$. Uncertainty in calculated reaction

254 probabilities was taken as the sum of the experimental uncertainty for $v_{d}$ and $v_{t}$ in quadrature. Reported

255 uncertainties on absolute mass measurements are given as the repeatability of the balance summed in

256 quadrature for two measurements, or $\pm 0.14 \mathrm{mg}$. Uncertainties reported for cumulative ozone uptake are

257 reported from a propagation of errors analysis on eq. 4 considering uncertainty on $v_{d}^{t}$ and the chamber

258 ozone concentration. The total uncertainty on molar uptake was determined by summing uncertainty at

259 each time step in quadrature.

260 3. Results and Discussion

$261 \quad 3.1$ Rates of mass accretion to glass plates

262 Measurements of total mass accretion to glass plates as a function of time deployed are shown in Fig. 2.

263 The figure shows the absolute mass accreted and indicates a general trend of increasing mass with more

264 time spent in the field. Rates of mass accretion were normalized to the area of the upward facing top of

265 the plate. Note that plates were placed on wire racks to avoid direct contact with actual indoor surfaces

266 and enable testing of $\mathrm{O}_{3}$ removal both upper and lower surfaces. This protocol resulted in exposure of 
267 both the top and bottom of glass plates to air (see Figure S1). In the results presented here, only the top

268 surface and sides were exposed to the ozone deposition test chamber. Given that plates were deployed in a

269 horizontal orientation, and were not processed to remove settled particles, we expect the surface film to be

270 comprised of both settled particles and sorbed organic compounds. However, as will be discussed

271 subsequently, mass accretion rates were normalized to the top area of plates because measured

272 magnitudes are in the range that appears predominantly due to deposition of coarse-mode particles and

273 rates of dustfall [34,36].

274 Weschler and Nazaroff [33] summarize the range of magnitudes of mass accretion of particles and

275 SVOCs to surfaces in models and in previous empirical studies. Their work reports a range of mass

276 accretion rates due to adsorption of gas-phase organics in the range of 30-300 $\mu \mathrm{g} /\left(\mathrm{m}^{2} \mathrm{~d}\right)$ [33]. This

277 reported rate is approximately 1-2 orders of magnitude lower than the accretion rates observed in this

278 study. Mass accretion rates observed here are in general agreement with the upper limit of the range

279 reported by Weschler and Nazaroff [33] to include deposition of coarse mode particles of 20-9000 $\mu \mathrm{g} /\left(\mathrm{m}^{2}\right.$

280 d). For example, after 56 days in the field, glass plates in the MV office and NV residence accreted $\sim 0.50$ -

$2810.78 \mathrm{~g} / \mathrm{m}^{2}$ of additional mass, or $9000-14,000 \mu \mathrm{g} /\left(\mathrm{m}^{2} \mathrm{~d}\right)$. The average mass accretion rate across all

282 collected plates is $10,600 \mu \mathrm{g} /\left(\mathrm{m}^{2} \mathrm{~d}\right)$ in the MV office vs. $18,500 \mu \mathrm{g} /\left(\mathrm{m}^{2} \mathrm{~d}\right)$ in the $\mathrm{NV}$ residence, and a one-

283 tailed t-test comparing higher accretion rates in the NV residences vs. MV office is at the threshold of

284 statistical significance $(p=0.054)$. The range of mass accretion shown in Figure 2 is also in reasonable

285 agreement with experimental results of dustfall rates in the literature. Edwards et al. [40] reported mean

286 values of 2200 and $3700 \mu \mathrm{g} /\left(\mathrm{m}^{2} \mathrm{~d}\right)$ in the summer and winter, respectively, in a study of four homes in

287 New Jersey, USA. In a study of 559 Canadian homes meeting a specified cleaning protocol, the reported

288 median dustfall rate was $10,000 \mu \mathrm{g} /\left(\mathrm{m}^{2} \mathrm{~d}\right)$ [41]. Thus, the exposure of the bottom face of the plate likely

289 introduced a small, acceptable error $(<3 \%)$ to the mass accretion rates determined here. 
(a)

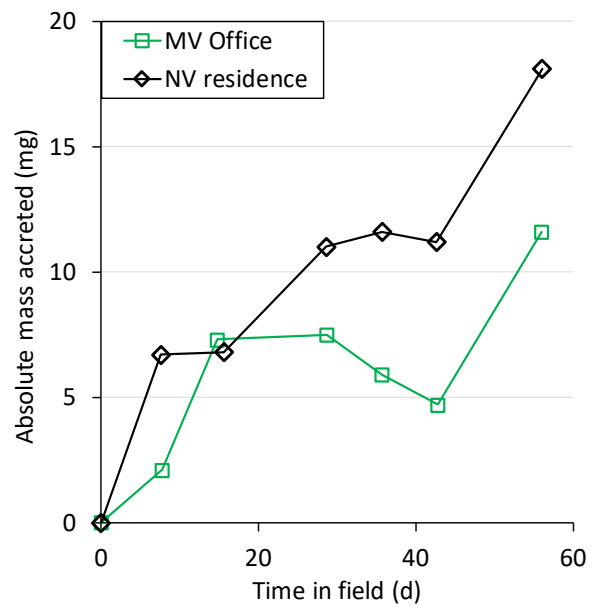

(b)

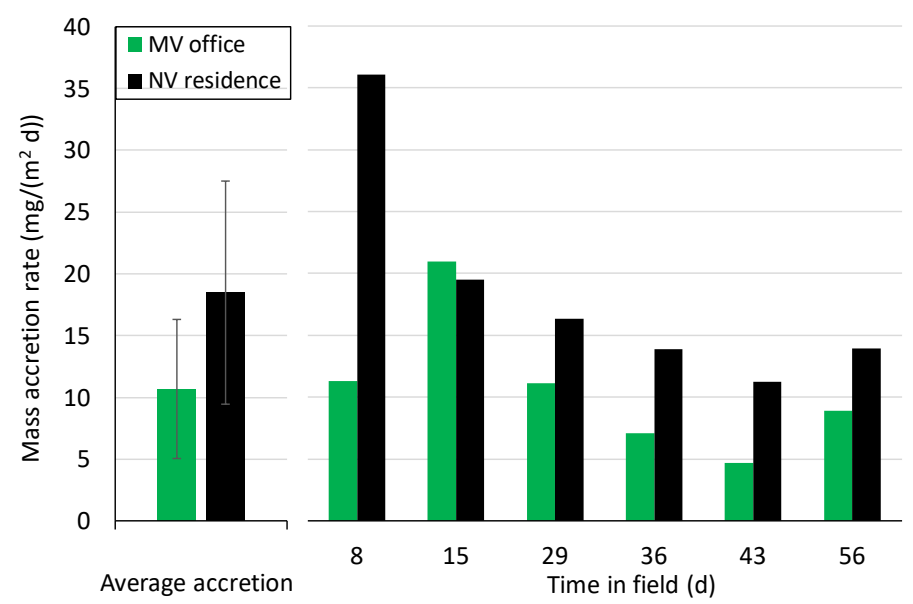

Fig. 2. Summary of mass accretion to test plates in two field environments: mechanically ventilated (MV) office and naturally ventilated (NV) residence. Panel a) shows absolute mass accretion while panel b) shows accretion rates. The average mass accretion rate $\left(\mathrm{mg} /\left(\mathrm{m}^{2} \mathrm{~d}\right)\right)$ was calculated as the arithmetic mean of seven mass accretion rates measured over seven weeks. Error bars on average accretion rate are the standard deviation of the mean mass accretion rate. Uncertainty on each estimate of absolute mass accreted is $\pm 0.14 \mathrm{mg}$ as described in the text.

While the mean mass accretion rate in the MV and NV locations are on the threshold of statistical significance in their difference, the magnitude of the difference in all but one sequential measurement of mass accreted to plates in the NV residence is consistently larger than that accreted to the MV office, and greater than the propagated uncertainty in the mass measurement from the analytical balance (i.e., measurement $>0.19 \mathrm{mg}$ ). We speculate the consistent difference between the MV and NV plates is due to lack of particle filtration in the NV residence which led to higher indoor particle concentrations and greater deposition flux of particles to the sample surface. Previous studies in Singapore of MV vs. NV residences indicate NV environments have a higher proportion of outdoor particulate matter present indoors than MV environments [42,43].

\subsection{Ozone reactivity of plates with accreted mass}

\subsubsection{Parameterizing transient $\mathrm{O}_{3}$ removal to surfaces}

The deposition of $\mathrm{O}_{3}$ to indoor surfaces is typically parameterized according to equation 5 , where the resistance uptake model ascribes resistances to removal due to transport from a well-mixed bulk core through a concentration boundary layer and subsequent reaction with the surface [27]. Across ozone 
311 deposition experiments, chamber conditions were held constant with the exception of changes in the

312 accreted mass on the glass plate. Therefore, observed changes in $v_{d}$ can be attributed to the accreted mass

313 present on the glass plate. An illustrative result showing the data collected during an experiment is

314 provided in Figure S4.

315 As discussed previously in Section 3.1, it appears that the majority of the accreted mass to the glass plates 316 deployed to field environments is derived from deposited particles. Thus, a recent study of ozone 317 reactions occurring on various indoor dust samples [32] provides a relevant basis for comparison for 318 ozone sink strengths. Deposition velocities reported in the first 90 min of each experiment, when 319 observable values are reported, are generally in the range of 0.002-0.025 cm/s across all plates with 320 accreted mass (see Figure S5). These values are roughly consistent with steady-state $v_{d}$ converted from $321 \mathrm{O}_{3}$-dust reaction rates in Vibenholt et al. [32] who report a range of values from $0.008-0.29 \mathrm{~cm} \mathrm{~s}^{-1}$. We 322 speculate that higher dust loadings in those experiments ( 1 g vs. $~ 0.01$ g here) explains the generally 323 higher deposition and observation of removal over $>12 \mathrm{~h}$ time-scales not observed in this study. It is 324 worth noting that $v_{d}$ reported in both studies are under reaction-limited conditions as the Vibenholt et al. 325 study was conducted in a FLEC cell operated at very high air exchange rate (AER) while for the 326 conditions of this study surface resistance contributes $>99 \%$ of total resistance for all experiments.

327 Ozone removal was highest initially and decayed for the duration of the experiment until a steady-state 328 removal indistinguishable from that of background removal was reached. Reaction probabilities for each 329 plate are reported in Table 1; values are arithmetic averages across each hour of the experiment for which $330 \gamma$ could be calculated from removal statistically higher than that of the background chamber surfaces. In 331 general, with additional time deployed to the field, reported reaction probabilities increased and $\mathrm{O}_{3}$ 332 removal persisted for longer periods of testing in the laboratory chamber. 
Table 1. Summary of regression parameters and time-averaged reaction probabilities across the first four hours of each experiment of ozone reactivity with deployed plates.

\begin{tabular}{|c|c|c|c|c|c|c|c|c|c|c|c|c|c|c|}
\hline & \multicolumn{7}{|c|}{ MV office } & \multicolumn{7}{|c|}{ NV residence } \\
\hline & \multicolumn{3}{|c|}{ Regression\% $^{\%}$} & \multicolumn{4}{|c|}{ Rxn. Probability ${ }^{\#}, \gamma \times 10^{-6}$} & \multicolumn{3}{|c|}{ Regression } & \multicolumn{4}{|c|}{ Rxn. probability, $\gamma \times 10^{-6}$} \\
\hline & $\begin{array}{c}\beta \\
\left(\mathbf{m i n}^{-1}\right)\end{array}$ & $\begin{array}{c}\text { SE } \\
\times 10^{-3} \\
\end{array}$ & $\mathbf{r}^{2}$ & $\begin{array}{c}0-1 \\
\text { h }\end{array}$ & $\begin{array}{c}1-2 \\
\text { h }\end{array}$ & $\begin{array}{c}2-3 \\
\text { h }\end{array}$ & $\begin{array}{c}3-4 \\
\text { h }\end{array}$ & $\begin{array}{c}\beta \\
\left(\mathbf{m i n}^{-1}\right)\end{array}$ & $\begin{array}{c}\mathrm{SE} \\
\times 10^{-3} \\
\end{array}$ & $\mathbf{r}^{2}$ & $\begin{array}{c}0-1 \\
\text { h }\end{array}$ & $\begin{array}{c}1-2 \\
\text { h }\end{array}$ & $\begin{array}{c}2-3 \\
\text { h }\end{array}$ & $\begin{array}{c}\text { 3-4 } \\
\text { h }\end{array}$ \\
\hline $\mathbf{0} \mathbf{d}$ & 0.045 & 5.2 & 0.54 & 0.74 & 0.06 & - & - & 0.045 & 5.2 & 0.54 & 0.74 & 0.06 & - & - \\
\hline $8 \mathrm{~d}$ & $0.026^{*}$ & 2.9 & 0.62 & 0.70 & 0.01 & - & - & $0.024 *$ & 2.1 & 0.29 & 1.0 & 0.34 & 0.23 & - \\
\hline $15 \mathrm{~d}$ & $0.020 *$ & 1.4 & 0.62 & 1.3 & 0.41 & - & - & $0.031^{*}$ & 1.9 & 0.33 & 1.6 & 0.43 & 0.01 & - \\
\hline $29 \mathrm{~d}$ & $0.013^{*}$ & 0.68 & 0.70 & 1.1 & 0.55 & - & - & $\begin{array}{c}0.0093 \\
* \\
\end{array}$ & 0.46 & 0.51 & 1.6 & 0.76 & 0.55 & 0.57 \\
\hline $36 \mathrm{~d}$ & $0.019 *$ & 2.0 & 0.09 & 1.2 & 0.38 & 0.16 & - & $0.025^{*}$ & 0.61 & 0.47 & 1.8 & 0.82 & 0.60 & 0.46 \\
\hline $42 \mathrm{~d}$ & 0.019 & 1.7 & 0.35 & 1.2 & 0.24 & 0.06 & - & $0.013^{*}$ & 0.65 & 0.67 & 1.5 & 0.72 & 0.46 & 0.18 \\
\hline $56 \mathrm{~d}$ & 0.018 & 2.0 & 0.23 & 1.2 & 0.29 & 0.17 & 0.15 & 0.013 & 0.61 & 0.75 & 1.8 & 0.83 & 0.48 & 0.19 \\
\hline $\begin{array}{c}\text { Field } \\
\text { Blank }\end{array}$ & 0.046 & 4.7 & 0.53 & 1.3 & 0.07 & - & - & 0.051 & 2.5 & 0.61 & 1.5 & 0.08 & - & - \\
\hline
\end{tabular}

In general, the parameterization of the time-variant reaction probability with equation 6 resulted in $r^{2}$ values of the regression that were typically $>0.5$ (see Figure S6 for examples of the regression). Several experiments had low $r^{2}$ values $(<0.4)$ but are included in subsequent analyses for completion and to facilitate the goals of the regression analysis to enable statistical comparison across experiments. The analysis of transient decay data also enables determination of the dynamics of ozone reactions to accreted masses that would be obscured by solely comparing the cumulative $\mathrm{O}_{3}$ removed as in Section 3.2.2. For example, the data reported in Table 1 demonstrate that as larger masses accrete to surfaces, increasing periods of time are required to increase cumulative $\mathrm{O}_{3}$ removal.

Across plates deployed in both the MV office and the NV residence, values of $\beta$ decreased as plates were deployed for longer periods. This trend continued until approximately 42 days of deployment (Table 1). From 42-56 days, slopes of the regression appear to stabilize at approximately $\beta=0.013-0.019$. Note that higher values of $\beta$ indicate the magnitude of $\gamma$ is "decaying" more rapidly than for lower values of $\beta$. This 
observation is also observed in that measurable values of $\gamma$ persisted into 3-4 hours of the experimental testing only for glass plates deployed for $56 \mathrm{~d}$ (MV office) or 29 days or greater (NV residence).

357 Statistical significance of differences in $\beta$ were determined by calculating z-scores from the difference in 358 slopes divided by the difference in the standard error of the slopes of the regression. The detailed 359 procedure is described in the Supporting Information. A summary of $p$-values for comparisons between 360 each plate and the preceding plate, as well as each plate compared to the 0 day plate, are provided in 361 Tables S1 and S2 of the Supporting Information. It appears that surface mass accretion results in 362 significant differences in $\mathrm{O}_{3}$ reactivity, especially in the first month of deployment. Differences in $\beta$ are 363 not statistically distinguishable when comparing longer deployment periods for plates deployed in MV 364 offices or $\mathrm{NV}$ residences, e.g., the plates deployed for $36 \mathrm{~d}$ and $42 \mathrm{~d}$ are statistically similar, as are plates 365 deployed for $42 \mathrm{~d}$ and $56 \mathrm{~d}$, for the MV office. For the NV residence, the plate deployed for $42 \mathrm{~d}$ is 366 similar to the plate deployed for $56 \mathrm{~d}$.

368 It appears that for glass plates, accretion of mass to the surface of the plate results in a general trend of 369 increasing $\mathrm{O}_{3}$ reactivity. The relationship between mass accretion and cumulative $\mathrm{O}_{3}$ removed is explored 370 in Fig. 3, which presents cumulative $\mathrm{O}_{3}$ removed as a function of mass accreted (panel a) and the average 371 reaction probability as a function of total mass accreted (panel b). The period of 15-200 minutes was 372 selected to calculate the cumulative $\mathrm{O}_{3}$ removal and the average $\gamma$. Cumulative $\mathrm{O}_{3}$ uptake to the accreted 373 mass is in the range of 20-90 nmol (Figure 3a), with a general increasing trend with greater accreted mass 374 to the plate for both MV and NV environments. Variance in the observed cumulative $\mathrm{O}_{3}$ removed was 375 similarly and relatively well-explained by the mass accreted to the plate for both MV and NV 376 environments $\left(r^{2}=0.75-0.76\right)$. 
(a)

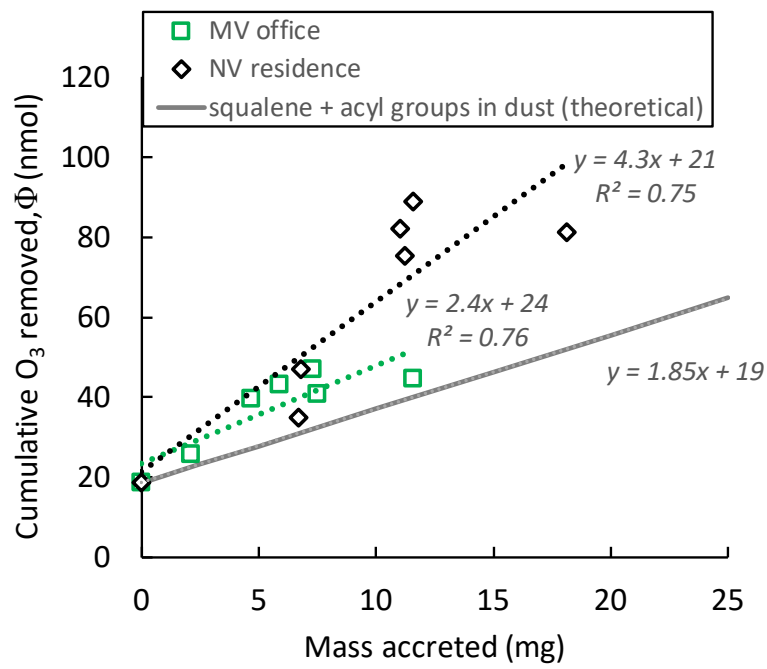

(b)

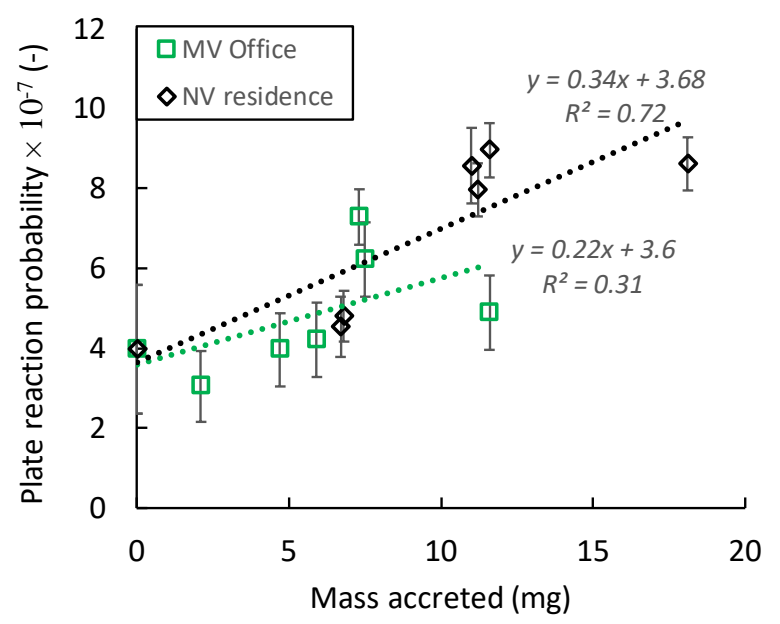

Two pathways are typically considered as mechanisms of $\mathrm{O}_{3}$ reaction with indoor surfaces. Ozone may

Fig. 3. Panel a) Cumulative $\mathrm{O}_{3}$ a function of mass accreted to field deployed glass plates. Cumulative uptake is determined from the period 15-200 minutes following the injection of ozone into the chamber. The theoretical uptake from squalene and acyl groups assumes accretion of mass with reaction sites from human-derived constituents onto a surface with the same initial reactivity (that is, $0 \mathrm{mg}$ of accreted mass) as the clean glass plates used in the NV and MV environments. Panel b) Reaction probability as a function of accreted mass.

The slopes shown in Figure 3a provide a proxy for the total reactivity of the accreted surface mass. The intercept is indicative of the reactivity of a clean plate, that is, the plate with no accreted mass from deployment to a field environment. The cumulative $\mathrm{O}_{3}$ removal to a clean glass plate was $19 \mathrm{nmol}$. The results shown in Figure 3a indicate that $4.3 \mathrm{nmol} \mathrm{O}_{3}$ was removed per mg of accreted mass for the NV residence vs. $2.4 \mathrm{nmol} \mathrm{O}_{3}$ per mg of accreted mass for the MV office. The $p$-values for slopes of the regressions in Figure 3a were statistically significant for both the MV and NV environments $(p=0.011$ and 0.011, respectively), which together with relatively high $r^{2}$ values implies mass accreted is a meaningful predictor of observed changes in cumulative $\mathrm{O}_{3}$ removal. The data reported in Figure 3a indicate that the mass accreted in the NV residence results in nearly twice the cumulative surface $\mathrm{O}_{3}$ removal compared to the MV office. However, a comparison of the standard error of the difference between the slopes shown in Figure 3a is calculated and is not statistically significant $(p=0.13)$. react with the accreted mass via catalytic degradation [32] or via the Criegee mechanism at carbon double 
bonds present in organic compounds in the accreted mass [5,32,44]. Previous studies, summarized by Weschler [45], show that the presence of humans in indoor spaces results in transfer of skin flakes (desquamation) and skin oils to indoor surfaces. These human-derived constituents contain compounds, namely squalene [46] and acyl groups [47], that may act as $\mathrm{O}_{3}$ surface reaction sites. The subsequent 401 analysis quantitatively evaluates the extent to which human-derived skin flakes and skin oils may explain 402 the observed removal to accreted mass on glass plates deployed to the MV and NV test environments.

403 Weschler et al. [48] estimate that dust contains approximately $60 \mu \mathrm{g}$ of squalene per gram. This is 404 equivalent to $150 \mathrm{nmol}$ of squalene present in each gram of accreted dust. There are six available double 405 bonds in a squalene molecule with which $\mathrm{O}_{3}$ may react [49]. In addition to squalene, there are other co406 occurring compounds present in human skin oil that also contribute unsaturated sites where ozone chemistry can occur. Pandrangi and Morrison [47] estimate that the molar fraction of unsaturations are 408 split between acyl groups (0.48) and squalene (0.44). Combining squalene and acyl groups, there are 409 available unsaturated reaction sites to remove $12.5 \mathrm{nmol}$ of $\mathrm{O}_{3}$ per nmol of squalene present in dust.

410 Normalizing by the previously noted mass of squalene in dust yields a ratio of $\sim 1.85 \mathrm{nmol}$ of $\mathrm{O}_{3}$ removal 411 due to squalene and acyl groups for every mg of accreted dust.

412 The previous estimate of the reactivity of squalene and acyl groups in particles calculated from the 413 literature, $1.85 \mathrm{nmol} \mathrm{O}_{3} \mathrm{removal} / \mathrm{mg}$ of accreted mass, can be compared with the reactivity of the accreted 414 mass calculated using equation 4 . The theoretical $\mathrm{O}_{3}$ removal due to squalene and acyl groups in dust is 415 shown in Figure 3a, with the same intercept as a cleaned glass plate. Comparing the slope of the 416 theoretical squalene and acyl groups line with slopes from plates deployed in the two field environments 417 shows that $42 \%$ ( $N V$ residence) and $75 \%$ (MV office) of $\mathrm{O}_{3}$ may be attributed to these components on 418 human skin oil. Note again that this analysis assumes, as discussed in Section 3.1, that particles or dust 419 are the predominant contributor to the accreted mass observed here.

420 The calculation of $42-75 \%$ of the total removed $\mathrm{O}_{3}$ as due to skin oil constituents implies other $\mathrm{O}_{3}$ 421 reactive constituents are also present in the accreting mass. A recent study of heterogeneous oxidation of 
422 squalene with $\mathrm{O}_{3}$ reported reactive uptake coefficients of [4.0-4.3] $\times 10^{-4}$ [50]. Values of plate reaction

423 probability reported here are much lower, with average values between [2-9] $\times 10^{-7}$ (Figure 3b). We

424 speculate this difference is a result of other compounds present in the accreting mass, as well as a

425 relatively low total accreted mass and potential for oxidation of highly reactive compounds like squalene

426 to occur while aging in the field. A study of the chemical composition of house dust reports total carbon

427 content on the order of $23-33 \%$ by mass [51,52]. Metals are shown to be a contributor to the indoor dust

428 composition, e.g., calcium levels of between 5-7\% by mass are reported in two studies of the composition

429 of house dust [41,52]. While the form of calcium in dust is not reported, there is precedence in the

430 literature that ozone reactions with, for example, calcium carbonate, will not proceed via irreversible

431 deposition, but rather reversible adsorption [53]. Given that the composition of indoor dust is expected to

432 be highly variable [41], this discussion is speculative and intended to be illustrative of the potential for

433 sources of lower reactivity compounds in masses accreting to indoor surfaces. The need for further study

434 of oxidation on indoor accreted mass paired with chemical composition of the accreted mass is noted.

$435 \quad$ 3.2.3 Study limitations and future directions

436 It is worth noting that plates were deployed in real field environments with low, but non-zero $\mathrm{O}_{3}$

437 concentrations; the $\mathrm{O}_{3}$ reactivity reported from testing in the laboratory does not account for oxidation

438 reactions that are likely to have occurred while the plates were deployed. Continuous interactions of

439 ozone with indoor surface films while deployed can reduce concentrations of surface unsaturated sites by

440 oxidation. Therefore, the estimates of the reactivity of the surface film reported here are likely

441 underestimating the true reactivity of the accreted mass. It is possible that the indoor concentration of

442 oxidants, rather than a difference in the amount or chemical makeup of the accreted mass, may be the

443 driver of the observed differences in reactivity between the NV residence (no filtration, frequently open

444 windows) and MV office (filters present in HVAC system, windows never open). We parameterized the

445 changing reaction probability using first-order kinetics to enable regression analysis, effectively treating

446 the changing reaction probability as a proxy for the changing density of surface reaction sites. It is 
447 possible that these dynamics could be more mechanistically explained if surface concentrations of

448 unsaturated sites in the accreted mass were known.

449 We tested field blanks where cleaned glass plates were deployed inside sealed polypropylene bags for the

450 duration of their deployment to the field. However, we speculate that the mass observed on the field blank 451 plates was unacceptably influenced by water vapor condensing on the plate that penetrated the consumer 452 grade polypropylene storage bag during the deployment. There are limited points of comparison in the 453 literature to either inform or compare the quality assurance measures taken here. In a study of surface 454 films on windows, Liu et al.[34] show that field blank Kimwipes, which were waved in the indoor air of 455 the field environment but were not in contact with the target window, contained $24 \%$ of the average 456 sample value of $n$-alkanes and $1 \%$ of the sample concentrations of polar compounds. Wallace et al. [36], 457 who conducted a study using collection methods similar to those described here, investigate the potential 458 for bare hand contact to contaminate surfaces, but do not isolate surfaces to consider as a field blank. 459 Further effort to standardize field sampling methods that use inert surfaces as media for experiments of 460 aging and surface film accretion in indoor spaces is warranted.

461 The findings of this study compel further quantitative research into the study of the reactivity of accreted 462 masses on surfaces as a function of building operation, building type, and indoor air pollution levels.

463 Characterization of surface-bound compounds pre- and post-ozonation would be beneficial in elucidating 464 the specific contributors to $\mathrm{O}_{3}$ reaction sites in mass accreted to indoor surfaces. There is precedence in 465 the literature for indoor and outdoor derived aerosols to differ in terms of chemical composition [54,55], 466 biological content [56], and water content [54]. Future studies should examine how these factors influence 467 the reactivity of the surface in addition to amount of mass accreted.

\section{4. Conclusions}

469 Accretion of mass to surfaces may alter reaction pathways by providing distinct reaction sites from those

470 of the original material. Previous studies of $\mathrm{O}_{3}$ removal to materials have used aged building materials in 471 studies, most notably carpet, drywall, and ceiling tile samples $[14,18,25]$. This study employed an initially 
472 inert, cleaned glass material to provide a baseline that allows isolation of the effect of the accreted mass

473 on surface $\mathrm{O}_{3}$ reactions. The results show that the accretion of mass to the glass plates resulted in as

474 much as a factor of 4.5 increase in cumulative $\mathrm{O}_{3}$ surface removal. Ozone reaction probabilities increased

475 with time spent in the field and mass accreted. Notable differences in the cumulative $\mathrm{O}_{3}$ removed per

476 mass accreted to the surface were observed for plates deployed to MV vs. NV environments, implying

477 building operation may affect how materials interact with indoor $\mathrm{O}_{3}$. In the range of $\sim 40-70 \%$ of total $\mathrm{O}_{3}$

478 removal may result from human skin and skin oil constituents present in the accreted mass. Given the

479 large extent of available surface area in indoor environments, further study of aging, mass accretion,

480 oxidation and oxidant cycling, byproduct formation and the integrated effect on indoor air quality and

481 human exposure is warranted.

482

483 Acknowledgements

484 This research was funded by Portland State University start-up funds and the Republic of Singapore's

485 National Research Foundation through a grant to the Berkeley Education Alliance for Research in

486 Singapore (BEARS) for the Singapore-Berkeley Building Efficiency and Sustainability in the Tropics

487 (SinBerBEST) Program. BEARS has been established by the University of California, Berkeley as a

488 center for intellectual excellence in research and education in Singapore. 


\section{References}

[1] J.L. Peel, M. Klein, W.D. Flanders, J.A. Mulholland, G. Freed, P.E. Tolbert, Ambient air pollution and apnea and bradycardia in high-risk infants on home monitors, Environ. Health Perspect. 119 (2011) 1321-1327. doi:10.1289/ehp.1002739.

[2] I. Romieu, F. Meneses, S. Ruiz, J. Huerta, J.J. Sienra, M. White, R. Etzel, M. Hernandez, Effects of intermittent ozone exposure on peak expiratory flow and respiratory symptoms among asthmatic children in Mexico City, Arch. Environ. Health. 52 (1997) 368-376. doi:10.1080/00039899709602213.

[3] J.I. Levy, S.M. Chemerynski, J.A. Sarnat, Ozone exposure and mortality: “An empiric bayes metaregression analysis,” Epidemiology. 16 (2005) 458-468.

[4] J.H. Seinfeld, S.N. Pandis, Atmospheric chemistry and physics: from air pollution to climate change, Wiley, 2006.

[5] C.J. Weschler, Ozone in indoor environments: concentration and chemistry, Indoor Air. 10 (2000) 269-288. doi:10.1034/j.1600-0668.2000.010004269.x.

[6] C. Chen, B. Zhao, C.J. Weschler, Assessing the influence of indoor exposure to "outdoor ozone" on the relationship between ozone and short-term mortality in U.S. communities, Environ. Health Perspect. 120 (2012) 235-240. doi:10.1289/ehp.1103970.

[7] C.J. Weschler, Ozone's impact on public health: contributions from indoor exposures to ozone and products of ozone-initiated chemistry, Environ. Health Perspect. 114 (2006) 1489-1496.

[8] L.J. Liu, P. Koutrakis, H.H. Suh, J.D. Mulik, R.M. Burton, Use of personal measurements for ozone exposure assessment: a pilot study., Environ. Health Perspect. 101 (1993) 318-324.

[9] M.L. Bell, R.D. Peng, F. Dominici, The exposure-response curve for ozone and risk of mortality and the adequacy of current ozone regulations, Environ. Health Perspect. 114 (2006) 532-536.

[10] C.J. Weschler, New directions: Ozone-initiated reaction products indoors may be more harmful than ozone itself, Atmos. Environ. 38 (2004) 5715-5716. doi:10.1016/j.atmosenv.2004.08.001.

[11] D.A. Kunkel, E.T. Gall, J.A. Siegel, A. Novoselac, G.C. Morrison, R.L. Corsi, Passive reduction of human exposure to indoor ozone, Build. Environ. 45 (2010) 445-452. doi:10.1016/j.buildenv.2009.06.024.

[12] E. Darling, G.C. Morrison, R.L. Corsi, Passive removal materials for indoor ozone control, Build. Environ. 106 (2016) 33-44. doi:10.1016/j.buildenv.2016.06.018.

[13] R.H. Sabersky, D.A. Sinema, F.H. Shair, Concentrations, decay rates, and removal of ozone and their relation to establishing clean indoor air, Environ. Sci. Technol. 7 (1973) 347-353. doi:10.1021/es60076a001.

[14] G.C. Morrison, W.W. Nazaroff, The rate of ozone uptake on carpets: Experimental studies, Environ. Sci. Technol. 34 (2000) 4963-4968. doi:10.1021/es001361h.

[15] R. Reiss, P.B. Ryan, P. Koutrakis, S.J. Tibbetts, Ozone reactive chemistry on interior latex paint, Environ. Sci. Technol. 29 (1995) 1906-1912. doi:10.1021/es00008a007.

[16] E.T. Gall, R.L. Corsi, J.A. Siegel, Barriers and opportunities for passive removal of indoor ozone, Atmos. Environ. 45 (2011) 3338-3341. doi:10.1016/j.atmosenv.2011.03.032.

[17] J.G. Klenø, P.A. Clausen, C.J. Weschler, P. Wolkoff, Determination of ozone removal rates by selected building products using the FLEC emission cell, Environ. Sci. Technol. 35 (2001) 25482553. doi:10.1021/es000284n.

[18] D. Rim, E.T. Gall, R.L. Maddalena, W.W. Nazaroff, Ozone reaction with interior building materials: Influence of diurnal ozone variation, temperature and humidity, Atmos. Environ. 125, Part A (2016) 15-23. doi:10.1016/j.atmosenv.2015.10.093.

[19] T. Grøntoft, M.R. Raychaudhuri, Compilation of tables of surface deposition velocities for $\mathrm{O}_{3}, \mathrm{NO}_{2}$ and $\mathrm{SO}_{2}$ to a range of indoor surfaces, Atmos. Environ. 38 (2004) 533-544. doi:10.1016/j.atmosenv.2003.10.010.

[20] O.A. Abbass, D.J. Sailor, E.T. Gall, Effect of fiber material on ozone removal and carbonyl production from carpets, Atmos. Environ. 148 (2017) 42-48. doi:10.1016/j.atmosenv.2016.10.034. 
[21] O.A. Abbass, D.J. Sailor, E.T. Gall, Effectiveness of indoor plants for passive removal of indoor ozone, Build. Environ. 119 (2017) 62-70. doi:10.1016/j.buildenv.2017.04.007.

[22] J. Shen, Z. Gao, Ozone removal on building material surface: A literature review, Build. Environ. 134 (2018) 205-217. doi:10.1016/j.buildenv.2018.02.046.

[23] G.C. Morrison, W.W. Nazaroff, Ozone interactions with carpet: Secondary emissions of aldehydes, Environ. Sci. Technol. 36 (2002) 2185-2192. doi:10.1021/es0113089.

[24] S.P. Lamble, R.L. Corsi, G.C. Morrison, Ozone deposition velocities, reaction probabilities and product yields for green building materials, Atmos. Environ. 45 (2011) 6965-6972. doi:10.1016/j.atmosenv.2011.09.025.

[25] C.J. Cros, G.C. Morrison, J.A. Siegel, R.L. Corsi, Long-term performance of passive materials for removal of ozone from indoor air, Indoor Air. 22 (2012) 43-53. doi:10.1111/j.16000668.2011.00734.x.

[26] P. Wolkoff, How to measure and evaluate volatile organic compound emissions from building products. A perspective, Sci. Total Environ. 227 (1999) 197-213. doi:10.1016/S00489697(99)00019-4.

[27] W.W. Nazaroff, A.J. Gadgil, C.J. Weschler, Critique of the use of deposition velocity in modeling indoor air quality, in: Model. Indoor Air Qual. Expo. Nagda NL Ed, American Society for Testing and Materials, Philadelphia, 1993. http://www.astm.org/DIGITAL_LIBRARY/STP/PAGES/STP13101S.htm (accessed July 20, 2017).

[28] E.T. Gall, J.A. Siegel, R.L. Corsi, Modeling ozone removal to indoor materials, including the effects of porosity, pore diameter, and thickness, Environ. Sci. Technol. 49 (2015) 4398-4406. doi:10.1021/acs.est.5b00023.

[29] W.W. Nazaroff, G.R. Cass, Mathematical modeling of chemically reactive pollutants in indoor air, Environ. Sci. Technol. 20 (1986) 924-934. doi:10.1021/es00151a012.

[30] R. Reiss, P.B. Ryan, P. Koutrakis, Modeling ozone deposition onto indoor residential surfaces, Environ. Sci. Technol. 28 (1994) 504-513. doi:10.1021/es00052a025.

[31] M.S. Waring, J.R. Wells, Volatile organic compound conversion by ozone, hydroxyl radicals, and nitrate radicals in residential indoor air: Magnitudes and impacts of oxidant sources, Atmos. Environ. 106 (2015) 382-391. doi:10.1016/j.atmosenv.2014.06.062.

[32] A. Vibenholt, P.A. Clausen, P. Wolkoff, Ozone reaction characteristics of indoor floor dust examined in the emission cell "FLEC,” Chemosphere. 107 (2014) 230-239. doi:10.1016/j.chemosphere.2013.12.048.

[33] C.J. Weschler, W.W. Nazaroff, Growth of organic films on indoor surfaces, Indoor Air. 27 (2017) 1101-1112. doi:10.1111/ina.12396.

[34] Q.-T. Liu, R. Chen, B.E. McCarry, M.L. Diamond, B. Bahavar, Characterization of polar organic compounds in the organic film on indoor and outdoor glass windows, Environ. Sci. Technol. 37 (2003) 2340-2349. doi:10.1021/es020848i.

[35] M.L. Diamond, S.E. Gingrich, K. Fertuck, B.E. McCarry, G.A. Stern, B. Billeck, B. Grift, D. Brooker, T.D. Yager, Evidence for organic film on an impervious urban surface: Characterization and potential teratogenic effects, Environ. Sci. Technol. 34 (2000) 2900-2908. doi:10.1021/es9906406.

[36] L.A. Wallace, W.R. Ott, C.J. Weschler, A.C.K. Lai, Desorption of SVOCs from heated surfaces in the form of ultrafine particles, Environ. Sci. Technol. 51 (2017) 1140-1146. doi:10.1021/acs.est.6b03248.

[37] B.K. Coleman, M.M. Lunden, H. Destaillats, W.W. Nazaroff, Secondary organic aerosol from ozone-initiated reactions with terpene-rich household products, Atmos. Environ. 42 (2008) 8234 8245. doi:10.1016/j.atmosenv.2008.07.031.

[38] E.T. Gall, R.L. Corsi, J.A. Siegel, Impact of physical material properties on ozone removal by several porous materials, Environ. Sci. Technol. 48 (2014) 3682-3690. doi:10.1021/es4051956. 
627

628

629

630

631

632

633

634

635
[39] E. Gall, E. Darling, J.A. Siegel, G.C. Morrison, R.L. Corsi, Evaluation of three common green building materials for ozone removal, and primary and secondary emissions of aldehydes, Atmos. Environ. 77 (2013) 910-918. doi:10.1016/j.atmosenv.2013.06.014.

[40] R.D. Edwards, E.J. Yurkow, P.J. Lioy, Seasonal deposition of housedusts onto household surfaces, Sci. Total Environ. 224 (1998) 69-80. doi:10.1016/S0048-9697(98)00348-9.

[41] P.E. Rasmussen, C. Levesque, M. Chénier, H.D. Gardner, H. Jones-Otazo, S. Petrovic, Canadian House Dust Study: population-based concentrations, loads and loading rates of arsenic, cadmium, chromium, copper, nickel, lead, and zinc inside urban homes, Sci. Total Environ. 443 (2013) 520529. doi:10.1016/j.scitotenv.2012.11.003.

[42] A. Chen, E.T. Gall, V.W.C. Chang, Indoor and outdoor particulate matter in primary school classrooms with fan-assisted natural ventilation in Singapore, Environ. Sci. Pollut. Res. Int. (2016). doi:10.1007/s11356-016-6826-7.

[43] E.T. Gall, A. Chen, V.W.-C. Chang, W.W. Nazaroff, Exposure to particulate matter and ozone of outdoor origin in Singapore, Build. Environ. 93, Part 1 (2015) 3-13. doi:10.1016/j.buildenv.2015.03.027.

[44] R. Criegee, Mechanism of Ozonolysis, Angew. Chem.-Int. Ed. Engl. 14 (1975) 745-752. doi:10.1002/anie.197507451.

[45] C.J. Weschler, Roles of the human occupant in indoor chemistry, Indoor Air. 26 (2016) 6-24. doi:10.1111/ina.12185.

[46] A. Wisthaler, C.J. Weschler, Reactions of ozone with human skin lipids: Sources of carbonyls, dicarbonyls, and hydroxycarbonyls in indoor air, Proc. Natl. Acad. Sci. 107 (2010) 6568-6575. doi:10.1073/pnas.0904498106.

[47] L.S. Pandrangi, G.C. Morrison, Ozone interactions with human hair: Ozone uptake rates and product formation, Atmos. Environ. 42 (2008) 5079-5089. doi:10.1016/j.atmosenv.2008.02.009.

[48] C.J. Weschler, S. Langer, A. Fischer, G. Bekö, J. Toftum, G. Clausen, Squalene and cholesterol in dust from danish homes and daycare centers, Environ. Sci. Technol. 45 (2011) 3872-3879. doi:10.1021/es103894r.

[49] L. Petrick, Y. Dubowski, Heterogeneous oxidation of squalene film by ozone under various indoor conditions, Indoor Air. 19 (2009) 381-391. doi:10.1111/j.1600-0668.2009.00599.x.

[50] S. Zhou, M.W. Forbes, Y. Katrib, J.P.D. Abbatt, Rapid Oxidation of Skin Oil by Ozone, Environ. Sci. Technol. Lett. 3 (2016) 170-174. doi:10.1021/acs.estlett.6b00086.

[51] L. Mølhave, T. Schneider, S.K. Kjærgaard, L. Larsen, S. Norn, O. Jørgensen, House dust in seven Danish offices, Atmos. Environ. 34 (2000) 4767-4779. doi:10.1016/S1352-2310(00)00104-7.

[52] C. Lanzerstorfer, Variations in the composition of house dust by particle size, J. Environ. Sci. Health Part A. 52 (2017) 770-777. doi:10.1080/10934529.2017.1303316.

[53] L. Li, Z.M. Chen, Y.H. Zhang, T. Zhu, J.L. Li, J. Ding, Kinetics and mechanism of heterogeneous oxidation of sulfur dioxide by ozone on surface of calcium carbonate, Atmos Chem Phys. 6 (2006) 2453-2464. doi:10.5194/acp-6-2453-2006.

[54] A.M. Johnson, M.S. Waring, P.F. DeCarlo, Real-time transformation of outdoor aerosol components upon transport indoors measured with aerosol mass spectrometry, Indoor Air. 27 (2017) 230-240. doi:10.1111/ina.12299.

[55] R. Balasubramanian, S.S. Lee, Characteristics of indoor aerosols in residential homes in urban locations: a case study in Singapore, J. Air Waste Manag. Assoc. 1995. 57 (2007) 981-990.

[56] T. Lee, S.A. Grinshpun, D. Martuzevicius, A. Adhikari, C.M. Crawford, J. Luo, T. Reponen, Relationship between indoor and outdoor bioaerosols collected with a button inhalable aerosol sampler in urban homes, Indoor Air. 16 (2006) 37-47. doi:10.1111/j.1600-0668.2005.00396.x. 